\title{
INDICIOS DE LA EXISTENCIA DE UNA CLASE EN FORMACION: EL EJEMPLO DE MEDINA DEL CAMPO A FINES DEL SIGLO XV (*)
}

\author{
M. ${ }^{\text {a }}$ Isabel del Val Valdivieso \\ Universidad de Valladolid
}

Decir que el desarrollo urbano, con todo lo que éste representa, provoca, entre otras cosas, una remodelación de la estructura social feudal, no es ninguna novedad. Como tampoco lo es, señalar que en la sociedad urbana bajomedieval se vislumbra la existencia de un grupo, que se interpone entre quienes ejercen el poder en todas sus facetas y el común propiamente dicho. Constatado esto se hace preciso definir la naturaleza de este "grupo" y sus características, pero antes de nada es necesario rastrear aquellos elementos que nos permitan afirmar decididamente su existencia y el significado de la misma. Parece tratarse de los primeros balbuceos de una nueva clase social, sin embargo ¿en qué se basa esta afirmación?, ¿cuales son los datos históricos que permiten formularla?. Son preguntas a las que hay que dar respuesta. Eso es lo que voy a intentar hacer en las páginas que siguen, tomando como ejemplo una próspera villa mercantil castellana: Medina del Campo. Pienso que el análisis de un caso concreto - sin perder de vista, desde luego, la situación general- permite profundizar en la problemática planteada, y por tanto alcanzar una respuesta más precisa.

Si hubiera que optar, para definir el tipo urbano al que Medina del Campo pertenece, entre las dos categorías de ciudades que, teniendo en cuenta su relación con los rasgos esenciales de la economía feudal, propone R. Hilton, incluiriamos a esta villa en aquella categoria que agrupa a los grandes centros urbanos surgidos de la acción combinada de la clase dirigente feu- 
dal, el estado y el capital mercantil, y que necesita gastar la parte del excedente campesino que le ha sido entregado, por diversos medios, tras su conversión en dinero en los mercados de lo que el mismo autor llama «pequeñas ciudades» (1). Es decir, Medina del Campo es un importante centro urbano cuyo mercado va mucho más allá del simple intercambio de excedentes campesinos y productos artesanales locales. Aquí el mercado representa un elemento fundamental, hasta tal punto que, en el siglo XV, consigue afianzar sus ferias, convirtiéndolas en las más importantes de todo el territorio de la corona castellana.

Teniendo esto en cuenta, se comprende por qué los ingresos producidos por el comercio ocupan un lugar de honor entre las potenciales fuentes de enriquecimiento con que cuentan sus habitantes. Indudablemente la renta feudal tradicional, la ganadería, la agricultura - sobre todo la viticultura - la práctica de diversos oficios artesanos, destacan, lo mismo que en todas partes, como actividades dispensadoras de notables beneficios económicos; junto a ellas, el comercio, a pequeña y gran escala, desempeña un papel más destacado que en otros núcleos. Esto explica que, aunque no represente un valor excepcional en el conjunto global de ingresos de la clase dominante, sí es para sus miembros un importante medio de obtención de recursos económicos (2). Y explica igualmente que en Medina del Campo, como en otros centros comerciales, ese enriquecimiento, logrado mediante la actividad mercantil, confiera a su sociedad unas características propias, entre las que no hay que desdeñar la constitución de un grupo social intermedio entre la clase dominante tradicional y el común propiamente dicho.

A la hora de estudiar un conjunto social dado, Medina del Campo en este caso, hay que tener en cuenta elementos de carácter social, económico y político. De esta forma se percibe la existencia de una sociedad, al frente de la cual aparece una clase integrada por elementos procedentes de la pequeña nobleza local, a los que se unen individuos y familias surgidos de las filas de los más destacados vecinos, que se han enriquecido, fundamentalmente, a través de la práctica del comercio. Este colectivo, aunque intenta salvaguardar muy celosamente la estructura establecida, no puede evitar la formación de una clase intermedia, que no se incorpora a los linajes tradicionales (en torno a los cuales se vertebra la clase dominante tradicional, y, por tanto, importante instrumento en el proceso de reproducción de la misma), pero que se despega cada vez más claramente del común de vecinos.

La progresiva constitución de ese grupo de vecinos con una situación económica lo suficientemente sólida como para aspirar a rivalizar con los linajes, pero sin capacidad real para dar el salto hasta ellos, provoca una serie 
de desajustes en la organización de la estructura social tradicional de la villa. A través de ellos ese grupo se va constituyendo como clase, a la vez que toma conciencia de su propia personalidad y especificidad, y que intenta, si no participar activamente en el poder, sí al menos controlar a quienes lo ejercen. La clase dominante mantiene el control del concejo y capitanea en beneficio propio las relaciones establecidas con el resto de los vecinos; pero ahora es seriamente contestada por quienes, apartados de las esferas desde donde el poder puede ser administrado, tienen los medios suficientes para controlar su práctica. Quizá el ejemplo más claro lo podemos encontrar en la larga querella que, como veremos más adelante, protagonizan los «hombres buenos exentos» contra los regidores medineses, acusados éstos, entre otras cosas, de cohecho y prevaricación.

Los síntomas de transformación parecen evidentes si atendemos a los abundantes intentos, individuales y/o colectivos de acceder a la más elevada clase social de la villa, o de participar directa y personalmente en el ejercicio del poder. Ya he indicado en otro lugar (3), cómo los linajes aceptan en su seno a nuevos individuos o familias que, enriquecidos mediante la práctica del comercio, el ejercicio de alguna acitividad artesanal, o los servicios, consiguen cruzar el foso que media entre la clase dirigente y el resto de los vecinos. También hay quienes, para salvar esa distancia, logran el estatuto de hidalguía, merced al cual se distancian del grupo de los exentos para pasar a formar parte de los privilegiados; pero esta opción provoca una agria contestación por parte de los pecheros, de forma que, aunque en principio no parece resultar una fórmula difícil de ser llevada a la práctica, en realidad no siempre es fácil conseguir ser aceptado como hidalgo. Como ejemplo citaré el caso de Alfonso de Carra Olmedo, Juan Domínguez, Juan Redondo, Alfonso Carpintero, Antón Velasco y Alfonso González, cuyo título no es reconocido por los vecinos de la villa que se amparan en una carta de la reina Isabel, en la que, como merced a los medineses, se establece que en adelante no podrá darse el título de hidalguía a ninguna persona que en 1474 fuera pechero (4). Por otra parte no hay que menospreciar la resistencia de la propia clase dominante, que sólo acepta abrirse e incorporar nuevos miembros en tanto esto es inevitable, por los beneficios concretos que un linaje puede recibir de la integración en el mismo de alguna nueva fortuna, o por los perjuicios que dicha incorporación pudiera evitar, en el sentido de suavizar la resistencia frente a ellos de los gobernados.

A pesar de las resistencias, la evolución social provoca, en primer lugar, una ampliación de la clase dominante propiamente dicha, lo que a su vez da lugar a ciertos desajustes en el seno de la misma, a través de los cuales 
se vislumbra su necesidad de ampliar y cimentar convenientemente su participación en el poder, y de obtener nuevos y más abundantes ingresos a través de esa misma participación. Esto, que es fruto, sin duda, de su necesidad de contar con suficientes recursos en numerario para mantener el nivel de vida que su situación social y la mentalidad de la época exigen, puede ser interpretado también como un deseo de resarcirse, al menos en parte, de la pérdida de los recursos que potencialmente podrían provenir de la práctica del comercio, a la que, por tener que centrar sus esfuerzos en el ámbito del poder político, no pueden dedicarse con la intensidad que sería necesaria, y que, en el caso de los recién llegados, habría tenido que ser, quizá, relegada o abandonada.

Ese ansia de obtención fácil de recursos abundantes en metálico, es sin duda la explicación de los abusos cometidos por los miembros del concejo, denunciados, como luego veremos, por los «hombres buenos exentos».

Paralelamente, y merced al dinero que gracias a las ferias corre abundantemente en Medina, se ha producido el enriquecimiento de algunos medineses, quienes, si todavía no han logrado ascender socialmente, pretenden acercarse lo más posible a la clase inmediatamente superior, despegándose del resto de sus convecinos. Para ello utilizan los privilegios conseguidos de la corona (los exentos del interior del recinto murado se enfrentan a los pecheros de los arrabales), y el «valor moral» que les proporciona su buena situación económica (al frente de los exentos se destaca claramente un grupo de enriquecidos).

¿Puede decirse, en relación con lo anterior, que se están produciendo cambios en la sociedad medinense?. Seguramente la contestación es afirmativa, porque parece que la capa superior de los exentos renuncia, de mejor o peor grado, más o menos conscientemente, a su vertebración en el seno de la clase dominante tradicional, y a un protagonismo directo en el ejercicio del poder político; en parte, desde luego, forzados por las circunstancias, pero en parte también porque si se carece de otras fuentes destacadas de ingresos, el comercio es la única actividad potencialmente enriquecedora. En estas condiciones la renuncia a una plena dedicación a la misma supondría la pérdida inmediata de recursos para quien lo protagonizara, dado que las ventajas derivadas del acceso a las esferas de poder político no se traducen siempre, ni inmediatamente, en ingresos económicos concretos. Evidentemente, esas ventajas son de otra índole, y no pueden ser plenamente capitalizadas si no se cuenta con una sólida posición socio-económica de partida, que en una sociedad feudal, como la que nos ocupa, exige la propiedad territorial, inmueble y/o ganadera en cantidad suficiente como para, con un aporte 
importante, pero no sustancial, proveniente de otras actividades, asegurar el mantenimiento y reproducción de su rango.

Pero, por supuesto, la facción de enriquecidos medineses que no puede dar el salto hacia la clase superior, no renuncia a constituírse en un auténtico grupo de presión: intenta controlar el ejercicio del poder que aquella monopoliza; pugna por compartir los beneficios económicos a los que esa clase tiene acceso a través del concejo, exigiendo su participación en el usufructo de los propios concejiles; y hace todo lo posible por desmarcarse del resto de los vecinos, especialmente de los pecheros de los arrabales, cuya condición de no exentos les resulta especialmente molesta, en cuanto les recuerda su condición real de «no privilegiados», que no pueden abandonar a pesar de la importante exención tributaria de que disfrutan. En parte podría decirse, siguiendo a Hilton, que la revuelta, y en este caso la resistencia, generalmente no violenta, que protagonizan los exentos de Medina del Campo, es la expresión de su descontento contra la forma en que está organizada la sociedad, en cuanto que esa organización les impide alcanzar su meta más preciada, que no es otra que la de integrarse en la clase dominante (5). Es esa imposibilidad la que juega a favor de su constitución como grupo diferenciado, germen de una nueva clase.

\section{INTENTO DE CONTROLAR EL EJERCICIO DEL PODER}

Consciente de sus intereses y de que en beneficio de los mismos era imprescindible poner freno al engrandecimiento de aquellos que pertenecen a una clase superior a la suya, la comunidad de hombres exentos está dispuesta a utilizar, con ese fin, cuantos recursos tiene a su alcance. Bien es cierto que no son muchos. Pero también es verdad que con sólo evitar los abusos, que regidores y otros poderosos protagonizan, elevarían un no desdeñable obstáculo a las aspiraciones de aquellos. $Y$ esto es, fundamentalmente, lo que van a hacer, procurando evitar en todo momento que cualquier representante de la autoridad actúe de forma contraria a la legalidad y a los intereses de los demandantes.

De esta forma consiguen, tras la oportuna denuncia, que en 1493 la corona intervenga, a través del corregidor, en el caso del prado El Rabanillo, que había sido ocupado por dos regidores, Pedro de San Andrés y Alvaro Gutiérrez (6). El mismo sentido parece tener su interés por asistir a las reuniones concejiles de las que los regidores, protagonizando la tendencia contraria por causas obvias, procuran alejarles (7). 
El propio corregidor es objeto de quejas. En 1503 los procuradores de los hombres buenos pecheros de la tierra, y el de los hombres buenos exentos de la villa, elevan, de común acuerdo, una protesta a la corona, motivada por lo que consideran un serio agravio: que el corregidor ha cambiado la hora de la vista de las causas relacionadas con la alcabala (8).

Esta atención preferente a los abusos de poder, les lleva a orientar su actuación contra los regidores, puesto que éstos gozan de la ventajosa situación en que les coloca su doble papel de cabezas de linaje y miembros de pleno derecho del concejo. Y lo van a hacer demostrando una gran habilidad, que sin duda les viene inspirada por la convicción de que para triunfar en su aspiración de «ser más» y aproximarse progresivamente a la clase dominante, les es preciso ralentizar el progreso de ésta y, sobre todo, evitar que sus miembros más destacados afiancen sus ventajas aprovechando precisamente su situación al frente de la villa. Pero la posición de aquellos está muy sólidamente asentada, y esto hace difícil la tarea. Sin duda, esta es la causa por la que se va a llevar hasta sus últimas consecuencias la presentación de quejas a la corona, culminando éstas en el pleito que se sigue, en los primeros años del siglo XVI, en el Consejo Real.

En 1487, como consecuencia de las quejas de los vecinos contra los regidores, está en marcha una pesquisa, cuya realización han ordenado los reyes ya en 1485, a la vista de la gravedad del caso. Surge de aquí una larga querella, uno de cuyos hitos destacados lo encontramos en el mes de marzo de 1489: el día 26 los reyes ordenan a Ramiro Núñez de Guzmán, corregidor de Medina del Campo, la realización de una nueva pesquisa sobre las irregularidades de que son acusados los regidores (9); este mismo día y el 28 toman ya algunas medidas contra éstos prohibiéndoles meter vino y mosto de fuera, aprovecharse de los prometidos que se dan al hacer la postura de las rentas, encargar las mensajerias a personas no pertenecientes a los linajes de Mercado y Pollino, meter el ganado en las dehesas de hierba destinada a caballos, mulas y animales de labranza, y coger leña de tipo y lugares prohibidos (10). También el 28 de marzo los reyes encargan al corregidor que, para investigar más a fondo sobre las irregularidades denunciadas, tome las cuentas de los propios y derramas de los últimos cinco años (11).

El conflicto sigue avanzando. En 1493 Sancho Díaz, como consecuencia del mismo, es desposeído provisionalmente del cargo de regidor, en tanto se desarrolla el juicio y se aclaran las graves acusaciones de que ha sido objeto (12). En 1497 el corregidor recibe la orden de velar por la utilización de los propios en beneficio de toda la villa y no de los regidores y procuradores, 
que se arrogan salarios abusivos. Todavía en los primeros años del siglo XVI encontramos noticias al respecto (13).

Precisamente a través de este pleito los exentos medineses buscan obtener algún triunfo que favorezca su causa, y por ello cuidan con esmero todos los pasos a dar, demostrando en todo momento esa habilidad de la que antes hablaba. Una clara muestra de esto la encontramos en la actuación de los procuradores, que saben aprovechar en beneficio propio cualquier diferencia que pueda surgir y enfrentar a los miembros de la clase dominante. No sólo participando en los conflictos que esas diferencias pueden provocar, sino también, y muy especialmente, mediante tácticas más sutiles. En este sentido destaca claramente la lista de testigos que son llamados a declarar en el ya mencionado pleito que les enfrenta con los regidores.

Entre estos testigos aparecen dos regidores, Alonso Nieto y Diego del Castillo (14), de quienes se consigue una clara acusación contra Pedro de Mercado y Alvaro de Lugo en su respuesta a la octava pregunta. Esta declaración, que sorprende si la ponemos en relación con las que hacen en sus restantes interevenciones, en las que exculpan, con mayor o menor convicción según los casos, a sus hermanos de clase, puede quizá explicarse en función de un posible enfrentamiento entre acusados y acusadores. Sorprende también - y esto, apuntando en la misma dirección, aboga en favor de la inteligencia política del procurador de los exentos- que Diego del Castillo acuse a otro regidor, el ya fallecido Alvaro Gutiérrez, a tres grandes personajes de la villa, Alonso de Quintanilla, el abad de la colegiata y el alcalde de la Mota, y a su compañero en la declaración, Alonso Nieto, regidor del linaje de Barrientos. Esto último puede hacer pensar en una rivalidad entre ambos, aprovechada convenientemente por los demandantes para obtener contra los encausados una suficiente cantidad (y calidad) de acusaciones, capaz de hacerles alcanzar la meta propuesta: la condena de los regidores y la represión y castigo de sus abusos (15).

Van incluso más allá, y llaman a testificar a personas pertenecientes a los linajes, logrando de ellos importantes acusaciones contra los encausados. Encontramos entre ellos a Diego Gómez, hijo de Juan del Castillo, y primo de Diego del Castillo, que no duda en señalar expresamente, en la quinta pregunta, a Sancho Díaz, y, en la cuarta, a su propio primo y a Pedro de San Andrés. Un antiguo fiel del concejo, que por lo tanto sabia de qué estaba hablando, se refiere en sus declaraciones a Alvaro de Lugo el Viejo, Alvaro Gutiérrez, Alvaro de Lugo, Pedro de Mercado y Pedro de San Andrés. Por su parte Rodrigo de Hebán (16), del linaje Pollino, inculpa a Alvaro Gutiérrez, del linaje de Sancho Ibáñez. 
Ahora bien, no siempre consiguen el fin perseguido, y alguno de los testigos, haciendo gala de gran péricia, consigue salir de la situación sin mencionar a nadie; así Juan Pollino, miembro de dicho linaje, que se conforma con señalar, al contestar a la segunda pregunta, que la mayoría de los regidores van al regimiento por fantasia de preçiarse de regidores mas que por procurar el vien de dicha comunidad que son obligados (17); mientras Fernando Alvarez de los Llanos, escribano, desvía la cuestión hacia las justicias de la villa, a las que acusa de no cumplir aquello que los regidores ordenan (18). También Juan Yañes en su respuesta a la sexta pregunta logra, con habilidad, evitar cualquier inculpación (19).

Si de este tipo de testigos pasamos a los representantes de los exentos, nos encontramos con algunos personajes destacados, entre los que no faltan arrendadores - como Gómez de Castro y Rodrigo Sánchez-, guardas y monteros de los términos del concejo - Pedro Gómez, Juan de Villalpando y Martín Gil-, algún antiguo procurador - Juan Caballero-, y varios pescaderos y carniceros como Juan de Medina, Juan Manso, Fernando Pérez, Juan Pérez y Juan de Zamora. $Y$ es de resaltar que siempre, en los temas en que estos testigos formulan acusaciones mencionando nombres concretos, se refieren a temas y personas de los que, como consecuencia de su oficio o función, tienen un profundo conocimiento, no dudando, incluso, a la hora de declararse partícipes y beneficiarios de los abusos que denuncian (20). Indudablemente hay quien habla de oídas, pero, además de declararlo así, estos testigos no hacen, en general, sino acusaciones de carácter superficial.

A la vista de lo anterior cabe preguntarse ¿Quienes son los acusados?. En este punto todo hace pensar en la existencia de cierto temor a la hora de citar nombres concretos, aunque, en la mayor parte de los casos, ese miedo se supera. Son así expresa y directamente mencionados Juan de las Heras, sobrino de Alvar Gutiérrez, los escribanos Ruy Martínez y Fernando Alonso de los Llanos, el abad de la colegiata, el alcalde de la Mota, Alonso de Quintanilla y Alonso Alvarez de los Ibanes, este último del linaje de Pollino. También aparecen en lugar destacado diez y seis regidores, de los cuales, en el momento en que se realiza el interrogatorio, uno (Gutierre Rodríguez de Medina, del linaje de los Pollino), es fraile en la Mejorada, seis han fallecido (Alvar Gutiérrez, Alvaro de Lugo el Viejo, Juan de Bobadilla, Luis Díaz, Rodrigo de Bobadilla el Viejo y Diego Barrientos), y nueve parecen estar en ejercicio (Juan de la Fuente, Sancho Díaz, Diego del Castillo, Pedro de Mercado, Alvaro de Lugo el Mozo- del linaje Morejón-, Pedro de San Andrés- yerno de Quintanilla-, García de Montalvo y Alonso Nieto). 
De todos ellos, el centro principal de todas las acusaciones es Sancho Díaz, del linaje de don Castellano, que quizá en ese momento se encontraba en inferioridad, debilitado, respecto al resto; esta circunstancia explicaría no sólo el cúmulo de acusaciones que, al parecer sin ningún temor, se acumulan sobre él, sino también el que como consecuencia de ellas fuera expulsado del regimiento (aunque no hay que olvidar que no es la primera vez que Sancho es objeto de graves acusaciones y que, como ya he señalado en la nota 12 , había sido ya penado anteriormente con la pérdida del cargo).

De entre los regidores en ejercicio acusados, habría que situar en los puestos inmediatamente posteriores a Díaz, pero a bastante distancia del mismo, a Pedro de Mercado y a Pedro de San Andrés; mientras que los dos testigos, Alonso Nieto (del linaje Barrientos) y Diego del Castillo ocupan un lugar discreto, encontrándose entre los menos mencionados: sólo Juan de la Fuente ocupa una posición mejor.

Si revisamos a los ya fallecidos, sin duda ninguna Alvar Gutiérrez y Alvaro de Lugo el Viejo son el principal objeto de las iras de los testigos, quienes atribuyen al primero algunos actos violentos (21). El resto apenas es acusado, pero si hubiera que jerarquizarlos, la posición intermedia la ocuparía Rodrigo de Bobadilla - del linaje de Mercado- y Diego de Barrientos, y la inferior Juan de Bobadilla, también de los Mercado, Alvaro de Bracamonte y Luis Díaz.

A la vista de todo esto parece claro que la comunidad de exentos, y seguramente el grupo más destacado de los mismos, no sólo aprovechan las posibles fricciones que pudiera haber entre las diversas facciones de la clase dominante, y la debilidad más o menos manifiesta de cualquiera de ellas, para intentar poner coto a sus posibilidades de dominio, sino que no dudan tampoco a la hora de formular sus acusaciones. Estas apuntan a cuestiones verdaderamente fundamentales desde dos puntos de vista.

Por un lado, se fijan en aquellos aspectos que con más facilidad podían hacer inclinar a su favor la voluntad real. Así les acusan en general de no cumplir con sus obligaciones de velar por el bien común, e incluso de no respetar sus propias decisiones (así lo hacen en la segunda pregunta); de atentar contra ordenanzas precisas, como la que prohíbe cortar iniesta y carrasco (octava pregunta); de meter ganado ovejuno y cabruno en la dehesa reservada para ganado caballar, mular y de labranza (22); de traer vino y mosto de fuera (undécima pregunta); y de amenazar al procurador de los exentos y a otras personas cuando se oponen a sus irregularidades (séptima pregunta) (23). 
Por otro lado, apuntan con gran precisión contra aquello que, o bien les perjudica muy especialmente, como la pretensión, denunciada en la segunda pregunta, de algún regidor, en este caso Pedro de Mercado, que ha intentado hacerles pagar martiniega, de la que por merced real son exentos; o bien contra comportamientos susceptibles de ampliar la red de solidaridades que contribuye a mantener la posición dominante de aquellos. En este último supuesto se encuadran las denuncias referentes a la protección que los regidores brindan a sus amigos cuando éstos traspasan en sus actuaciones la línea de la legalidad (preguntas segunda y séptima); a los acuerdos que realizan con algunos oficiales (y se menciona repetidamente a carniceros, pescaderos y candeleros) para obtener ventajas económicas subiendo los precios de las mercancías (preguntas segunda, quinta y décimotercera), para repartirse, previa apropiación ilegal, el prometido de las rentas, o para ceder éstas a aquel que, bajo cuerda, premiara económicamente al regidor que le apoyara para obtenerlas (esto parece que se hace, a tenor de lo contenido en las respuestas a la quinta pregunta, tanto en la renta de las sernas, como a la hora de adjudicar las tablas de las carnicerías y pescaderías).

Todo ello sin olvidar estorbar la comisión de otras irregularidades, en especial, a juzgar por la insistencia que en ello se hace, el abuso consistente en apoderarse de recursos provenientes de los propios, mediante la realización, real o supuesta, de misiones de representación del concejo fuera de la villa, cobrando por ello, según los denunciantes, cantidades superiores al monto de los gastos realizados y a su justo salario (24).

¿Qué consiguen con todo esto?. Desde luego no alcanzan éxitos espectaculares, pero no cabe duda de que de esta forma, aireando dentro y fuera de la villa todas las irregularidades protagonizadas por regidores y otros destacados medineses, consiguen evitarlas en parte, aunque sólo sea por el obstáculo que el simple conocimiento de las mismas representa: no hay que olvidar la expulsión de Sancho Díaz, que debió representar una seria advertencia. Logran también los exentos hacer gala de su poder y su pujanza socio-económica, al ser capaces, no sólo de defender su causa, sino de resistir en ella a lo largo de varios años, lo que supone un notable esfuerzo, tanto organizativo como económico. Este hecho, por otra parte, pone de manifiesto la propia conciencia de su personalidad que el grupo dirigente de los exentos tiene, y que lleva a Andrés de Medina, su procurador, a hablar de aquellos que viven por su sudor y trabajo, refiriéndose a ellos y en especial a los menos favorecidos de entre ellos (25).

Pero esto no es suficiente para lograr sus objetivos. Necesitan además, para afianzar su posición, participar de los frutos de las rentas de propios, 
y no sólo por la ventaja económica que ello representa, sino sobre todo porque de esa forma se aproximan más a quienes les preceden en la escala jerárquica social. Esta necesidad les anima a emprender otro tipo de acciones.

\section{INTENTO DE PARTICIPAR EN EL USUFRUCTO DE LAS RENTAS CONCEJILES}

Si era importante, para los fines de la comunidad de exentos, controlar la actuación del regimiento, y a través de ello poner coto a un mayor enriquecimiento de los integrantes de la clase dominante, la misma importancia tiene la posibilidad de participar de las rentas concejiles provenientes de los propios.

Los hombres buenos exentos, al estar obligados a contribuir en el pago de sisas y repartimientos, tienen que aceptar, aunque forzosamente, una carga fiscal superior a la que soportan aquellos con quienes pretenden igualarse. Dándose cuenta de los perjuicios socio-económicos derivados de esa circunstancia, pugnan constantemente por aligerar al máximo esa responsabilidad, recurriendo a todas las opciones a su alcance, desde la presentación de diversas disculpas coyunturales, al amparo de las cuales buscan excusar su participación, hasta la implicación en la misma de personas ajenas a esa obligación, pero que se ven involuntariamente inmersas en ella por la acción, consciente por supuesto, de nuestros exentos, que de esa manera consiguen hacer más liviana su contribución tributaria (26).

En 1419 los habitantes del recinto murado de Medina, cristianos, moros y judios, se ven beneficiados por una merced real que les exime durante diez años del pago de monedas. En marzo de 1475 los nuevos reyes confirman los usos, costumbres, privilegios y exenciones de esos medineses; pero será en 1477 cuando los reyes, explícitamente, aludiendo a los servicios que la villa les ha prestado en la guerra con Portugal, y a su deseo de ennoblecerla, confirman la merced de Fernando de Antequera que les hacía francos, libres y quitos de pedidos, monedas, moneda forera y martiniega (27). Evidentemente, este privilegio no les exime de participar en los repartimientos de la Hermandad ni en los gastos extraordinarios relacionados con el bien común de los habitantes de la villa.

En ocasiones, para hacer frente a esas obligaciones, se recurre al reparto de maravedís. Por una disposición general de 1433, sólo es posible repartir, sin contar con permiso real expreso, hasta un total de $3.000 \mathrm{mrs}$ (28). Lo insuficiente de esta cantidad, y las quejas y resistencias que el repartimiento suele provocar (29), hace que sea necesario el recurso a las sisas, sistema 
al que se recurre muy frecuentemente, incluso a la hora de hacer frente a la contribución a la Hermandad.

Preocupados por las condiciones físicas de la villa, los reyes, en 1489, dan las órdenes oportunas para que, lo que sobre del monto total de las rentas de los propios, una vez satisfechos los gastos ordinarios, se emplee en empedrar las calles y restaurar la cerca (30). Cinco años después, en 1494 , se habla de la sisa que se coge para hacer frente a los gastos de las mismas obras (31). Evidentemente algo ha sucedido. Por una parte, el esfuerzo económico que esas empresas representan parece ser mayor del previsto en un primer momento, pero también parece que el regimiento procura evitar que sean costeadas conforme se establecía en 1489. Es decir, se impone un pulso entre el concejo y la comunidad de exentos.

Estos son derrotados en el primer encuentro, si bien, como veremos, es una derrota parcial. De momento, en mayo de 1494 los reyes ordenan que sean los vecinos de las calles a empedrar quienes contribuyan en los dos tercios del gasto total de la obra, pagando cada cual lo que montare en su pertenencia; la villa tiene que pagar el otro tercio, pero no se especifica de qué manera, ni quien es «la villa», los vecinos o el concejo. A juzgar por otras noticias, ese tercio le corresponde a los primeros: pocos días después, el 30 de ese mes, tenemos noticias de que se ha levantado una queja, como consecuencia de que, para pagar los gastos derivados de las obras de la cerca y el empedrado, se ha impuesto, durante todo el año, una sisa de un cornado por libra sobre la venta de carne y pescado; el concejo lo justifica diciendo que los recursos provenientes de los propios no son suficientes, ni siquiera para satisfacer los gastos ordinarios y los derivados de los pleitos que tiene pendientes (no obstante lo cual, en octubre de ese mismo año, obtiene licencia real para tomar de esos propios hasta $100.000 \mathrm{mrs}$. para terminar la construcción de una tapia cortafuego, hasta tanto los reyes les libren los $200.000 \mathrm{mrs}$. correspondientes a ese año para continuar las obras de la cerca y el empedrado) (32).

La sisa es un método de recaudación utilizado muy frecuentemente, dándose el caso de recurrir al mismo incluso para pagar los gastos de los pleitos que la imposición de la propia sisa provoca (33). Y no es raro que se llegue a pleitear, dado que, con el afán de reducir su participación en cualquier tipo de gasto colectivo, los exentos procuran implicar en los mismos a otros grupos que objetivamente no tendrían ninguna responsabilidad al respecto. Se trata especialmente de los vecinos de los arrabales y de aquellos que van a las ferias. El concejo lo denuncia, y, cuando les interesa, los propios exentos lo reconocen (34). Pero esto no les cohíbe en absoluto, como tampoco 
lo hace la prohibición real referente a exigir a los foráneos que van a las ferias el pago de la sisa impuesta para pagar los $62.000 \mathrm{mrs}$. con que tienen obligación de contribuir al mantenimiento de la Hermandad (35).

En ocasiones los exentos llegan a involucrar a los hidalgos en el pago de las sisas, provocando, lógicamente, las airadas protestas de éstos. Así sucede en los últimos años del reinado de isabel cuando, para satisfacer el pago de un servicio se impone una sisa a todos los habitantes de la villa (salvo clérigos y religiosos) sin que ello supusiera perjuicio para los hidalgos. Esta fórmula es lo suficientemente vaga como para permitir que los exentos busquen el modo de implicar a los hidalgos. Estos, que dicen no querer ningún asiento con los hombres buenos exentos, exigen, tras conseguir el amparo real, que se les excluya de la contribución. Por esta razón los privilegiados «señalan» sus carnicerias, en las que esa sisa no se cobrará. Por su parte, los exentos, que se sienten agraviados por el acuerdo - por cuanto ellos, por merced real, están eximidos de todo servicio-, sacan a colación otra ocasión anterior en la que se impuso una sisa general a la que, dicen, contribuyeron todos, también los hidalgos, para satisfacer el servicio pedido para cubrir los gastos de dote y casamiento de las infantas. Amparándose en ese precedente, plantean dos posibilidades: o la sisa general, o acudir a los propios. El concejo se resiste, y alega lo habitual en estos casos, que los propios no son suficientes, porque, tras atender a los gastos ordinarios, lo sobrante lo han gastado ya en cosas cumplideras al servicio real y en atender a las necesidades públicas y colectivas de la villa (36).

Este pretender que sus obligaciones y necesidades económicas colectivas sean satisfechas por el concejo, empleando para ello parte de las rentas de propios, es otra de las fórmulas empleadas por los exentos para acercar su posición a las más notables familias de Medina. No dudan para ello en hacer ver, como en el caso que acabo de exponer, que ellos son tan «exentos», respecto a alguna contribución concreta, como los hidalgos y aquellos que, amparados de hecho en su preeminente situación, no pagan pechos, y reivindican por tanto que, o pagan todos, o no paga ninguno. Otras veces hacen contribuir a los foráneos, lo que supone una forma de lograr que los reyes soliciten al concejo, aunque sin éxito, para evitar males mayores, que pague de los propios la contribución a la Hermandad.

En otras ocasiones procuran identificar su propio interés con el general de la villa, tal y como sucede en el asunto de la compra de los prados de la Horcilla (véase la nota 6), que es presentado por los exentos como un asunto que afecta a toda la colectividad, y por tanto a satisfacer económicamente 
con las rentas concejiles, cuando parece beneficiarles fundamentalmente a ellos como comerciantes.

Y no paran ahí. En su afán por equipararse con aquellos a los que pretenden emular, buscan participar directamente del usufructo de las rentas concejiles: piden que sus procuradores, igual que los del concejo, sean pagados a costa de los propios. Y lo más importante es que logran para su causa el apoyo real. En algún caso consiguen convencer a los reyes para que el concejo les preste la cantidad necesaria (37). En otros se trata ya de la entrega de cantidades concretas para «ayuda» de la causa de los exentos (38).

Es decir, utilizando los diversos recursos a su alcance, la comunidad de exentos, merced a la acción de los más destacados de entre ellos, logra participar de los recursos concejiles aunque, indudablemente, el monto fundamental de los mismos se emplea en la realización de obras de carácter público (39), y en satisfacer los salarios, en ocasiones abusivos, de la justicia, regidores y oficiales del concejo. Esto les aproxima a la clase superior. Y esta aproximación exige, en contrapartida lógica, un despegue de la inferior, que, considerando colectivamente al grupo de los exentos (pues para este tipo de cosas tienen que actuar como un todo, aunque en su seno haya dos grupos claramente diferenciados) no puede ser sino la de los pecheros de los arrabales y de la tierra.

Respecto a los últimos (los pecheros de la tierra) las diferencias son claras, y las barreras existentes entre ellos también, por lo que, generalmente, no provocan preocupación a los vecinos del interior del recinto murado. Otra cosa distinta sucede con los habitantes de los arrabales, más próximos en el espacio, en la actividad económica y en el status social, y que tienen además intereses semejantes (no hay que perder de vista que esa nueva clase de los medios, aunque esté integrada fundamentalmente por los más destacados de los vecinos exentos, también se nutre de habitantes de los arrabales). Dado que, para alcanzar sus objetivos, los dirigentes de los exentos saben que tienen que centrar sus esfuerzos en diferenciarse conjuntamente de otros colectivos sociales, van a pretender marcar las distancias respecto a los vecinos de los arrabales, tal y como puede observarse en un tema tan complejo como el del cobro de la sisa que se impone sobre la venta de la carne. 


\section{DISTANCIAMIENTO DE LOS «HOMBRES BUENOS EXENTOS» RESPECTO A OTROS MEDINESES DE INFERIOR CONSIDERACIÓN SOCIAL}

En algunas ocasiones, como cuando en 1495 procuran la llegada de un corregidor concreto (Alonso Escudero) en vez de otro (Juan Pérez de Barradas), podemos ver actuando de común acuerdo al procurador de «los caballeros e hidalgos de los siete linajes», al de «los hombres buenos exentos que solian ser pecheros de las cuadrillas» y al de «los hombres buenos pecheros de la tierra» (40). Pero cada uno de estos tres colectivos, a los que hay que añadir el de los habitantes de los arrabales, cuentan con su propio sistema organizativo y de representación, que, en el caso de los exentos que ahora nos ocupa, es utilizado como instrumento de diferenciación respecto a los restantes pecheros.

Por lo que se refiere a los «hombres buenos pecheros» de la tierra, las cosas son más fáciles. La diferencia entre los vecinos de la villa y éstos está lo suficientemente marcada como para que, incluso, se establezca un trato distinto a la hora de señalar las demandas que los arrendadores pueden poner sobre los actos de compra-venta: a los vecinos de la villa cada semana una vez, y a los de la tierra una cada mes (41). El caso de los arrabales es distinto, por cuanto unos y otros se encuentran mucho más próximos en todos los aspectos. Por esto los exentos van a procurar marcar claramente las diferencias, y para ello utilizan, seguramente entre otros instrumentos, las sisas.

Como acabamos de ver, los exentos, con el fin de que su obligación tributaria fuera más llevadera, procuran involucrar en la misma a quienes no deben, entre los que están los vecinos de los arrabales. Estos, por su parte, van a presentar una firme resistencia, con lo cual, sin quererlo, contribuyen a la consecución de uno de los fines de aquellos: declararse diferentes al resto de los pecheros.

En los primeros años del siglo XVI, seguramente en 1503, se establece un mecanismo distinto para uno y otro ámbito a la hora de recaudar los $\mathrm{mrs}$. del servicio real: mientras los vecinos de muros adentro lo hacen mediante sisa, que se cobra en la carnicería, los de muros afuera recurren al repartimiento. $Y$ esto es lo que va a provocar el conflicto, por cuanto, desde el momento en que las carnicerías se encuentran en el interior del recinto murado, los de los arrabales se ven casi obligados a contribuir por partida doble. De ahí sus protestas y el consiguiente pleito. En la probanza de los testigos de los demandantes, presentada en 1514, se dice que son los exentos (y no el concejo) quienes imponen ese doble sistema, apuntando abiertamente a que 
son aquellos los que tienen interés en la existencia de un sistema que claramente les beneficia; y se dice también que la solución buscada por esos mismos exentos (que los vecinos de los arrabales compren la carne en la carnicería de los hidalgos, libre de sisa y próxima a su residencia) no es sino una falacia, puesto que ni el arrendador de la sisa permite que un pechero compre en esas tablas, ni los carniceros les atienden debidamente, pues les venden únicamente los despojos que no quieren los clientes principales (42). Dada esta situación, los de los arrabales, tras conseguir el favor real, intentan solucionar el conflicto proponiendo que el repartimiento se anule y que su contribución al servicio real se recaude también a través de la sisa. Pero no conseguirán hacer triunfar sus pretensiones.

Por supuesto los pecheros buscan, además de evitar el fraude que les convierte en contribuyentes por partida doble, aprovechar la circunstancia para hacer valer su pretensión de igualarse a los exentos: defienden su derecho a contribuir por sisa, abasteciéndose en las mismas carnicerías que ellos, pues, dicen, de esta forma no recibiría ningún daño la parte contraria. Hay otros datos aún más significativos, como el que, al levantar acta de la reunión que celebraron en el claustro del monasterio de San Sadornín Extramuros, el 1 de diciembre de 1513, para elegir procurador (fue elegido Juan de Topas), el escribano «se equivoque», y hable en el encabezamiento del acta de "vecinos, moradores y hombres buenos exentos de todos los arrabales de Medina del Campo» (43).

En este asunto los hombres buenos exentos saben defender su causa, y cuentan con el apoyo del concejo, a pesar de que objetivamente los intereses de unos y otros no sean los mismos, ni tampoco coincida su posición respecto al poder. El corregidor, en vez de optar por una de las dos opciones dadas por la reina (que los arrabales paguen también por sisa o que se les dé carnicería propia), decide mantener la situación existente; lo justifica diciendo que aceptar el pago mediante sisa para los habitantes de los arrabales perjudicaría a los exentos, porque eso daría pie a que alguno de aquellos se llamara exento no siéndolo.

A esto hay que sumar que el escribano del caso, en un exceso de celo a la hora de favorecer a una de las dos partes en conflicto, no duda en «perder" documentos fundamentales para los de fuera de los muros, cosa que éstos denuncian sin ningún resultado positivo (44). Por otra parte, los exentos logran también que algún escribano se equivoque alguna vez a su favor, a la hora de referirse a ellos, llamándoles escuderos en vez de exentos; y procuran actuar conjuntamente con el procurador de los caballeros e hidalgos de los linajes en asuntos de especial relevancia (45). 
Si de los hechos pasamos a los resultados, hay que observar que, seguramente, no es la masa toda de los exentos la que capitaliza el posible beneficio que de ello se deriva, sino sólo el grupo más destacado de entre ellos, aquellos que, pugnando por ascender, sin conseguirlo del todo, colaboran activamente en el cambio que representa la aparición de un grupo social nuevo. Este no se integra, porque no le es posible, en la clase dirigente urbana, pero se despega del común de los vecinos y comienza a potenciar nuevas formas de vida y de relación, propiciando también, lógicamente, el nacimiento de una nueva mentalidad (46).

A lo largo de todo este proceso las carnicerías, y los carniceros, juegan un destacado papel. La comercialización de la carne es uno de los más rentables medios de enriquecimiento; quizá por eso todo lo que gira en torno a su arrendamiento es uno de los motivos de más peso del pleito que enfrenta a exentos y regidores. Además, los mecanismos que rodean la venta de carne son utilizados por aquellos como instrumento para diferenciarse de los pecheros de los arrabales. Por estas razones las carnicerías pueden servir de ejemplo concreto e inmediato a la hora de ilustrar lo hasta aquí señalado.

\section{LAS CARNICERÍAS COMO INSTRUMENTO AL SERVICIO DE UNA CLASE EN GESTACIÓN}

Estudiando la dieta alimenticia de la época se colige con facilidad que la carne ocupa un lugar destacado en la misma. Aunque es cara, causa que lleva a algunos historiadores a considerarla un producto de lujo (47), su consumo estaba muy extendido, y no solamente merced a la cría de cerdos, los animales de corral y los provenientes de la práctica de la caza (48), también se comercializa abundantemente en las carnicerías. Estudiando las raciones que se dan a los pobres o residentes en hospitales, se observa que la carne es un producto que, en mayor o menor cantidad según los casos, se repite siempre, junto al pan y al vino (49), lo que parece poner de manifiesto la «popularidad» de tal alimento.

Para garantizar el abastecimiento de este producto, máxime en una villa en la que el porcentaje de transeúntes era elevado, las carnicerías se convierten en un elemento fundamental; por otra parte hay que tener en cuenta que proporcionan además otros productos necesarios a diversos artesanos (tales como sebo para candeleros y pieles para curtidores) (50).

Ahora bien, las carnicerias no cumplen sólo ese papel, son también una importante fuente de rentas para las arcas concejiles, y un medio de enrique- 
cimiento para äquellos que las atienden o arriendan (51). De esta forma participan, con especial protagonismo, en ese proceso de gestación de una nueva clase al que me vengo refiriendo, siendo utilizadas tanto como fuente imprescindible de ingresos para unos cuantos, como instrumento diferenciador y de control de aquellos de quienes se quieren distanciar. Esto último es lo que explica que ante la posibilidad de establecer una nueva carnicería en los arrabales, tal y como piden los vecinos de éstos, en el pleito que les enfrenta a la villa con motivo del cobro de la sisa, el colectivo de los exentos, amparados en este caso por el concejo, rechace tal posibilidad, alegando que están suficientemente abastecidos con las que existen en el recinto murado.

Consideradas desde el punto de vista alimentario, las carnicerías cumplen, junto con las pescaderías, la función de proveer de proteínas animales a los habitantes de la villa. Para ello ponen a su disposición, en distintas tablas, diversos tipos de carne, cuya calidad es controlada por los fieles, cumpliendo de esta forma el concejo su obligación de velar por el buen abastecimiento, en cantidad y calidad, de los medineses (52).

Tras la expulsión de los judíos, Medina parece contar con una carnicería para su población musulmana y dos para la cristiana. Estas últimas se localizan en la zona de San Francisco, donde está la del común de los vecinos, y en San Antolín y en la plaza de San Andrés, donde se ubica la reservada a caballeros, hidalgos, clérigos y frailes. En los últimos años del siglo XV, so pretexto de instalarse en una zona más apropiada, la clase dominante crea (más que traslada) otra carnicería en la plaza de San Juan. Los exentos se quejan por ello, sin duda porque esa duplicación de la carnicería de los poderosos podía perjudicarles; no obstante sus quejas no parece que lograran evitarla, pues en 1514, en el proceso del pleito con los vecinos de los arrabales, se dice que hay dos carnicerías en las que se vende carne sin sisa (53). La de San Francisco, es decir, la de los no privilegiados, parece crear ciertos problemas de higiene y limpieza, que son denunciados en 1480 por los vecinos de la Rua, el monasterio de San Bartolomé - que linda con las tablas situadas en la casa de Pedro del Busto-, y el bachiller García Terencio, regente de la cátedra de gramática del estudio de la villa; los demandantes basan su argumentación, tanto en que tal actividad perturba la devoción al crucifijo que se venera en dicho monasterio, como en los perjuicios que se ocasionan a la villa. Pero tienen que esperar casi veinte años, hasta 1499, para que se inicie el proceso de traslado de las carnicerías de San Francisco hacia la ribera del Zapardiel; el 30 de enero de ese año la villa pide a los reyes el preceptivo permiso para proceder al traslado. El proceso, a a partir 
de ese momento, es muy lento y, aunque el 21 de marzo de 1499 los monarcas dan su autorización, el cambio de emplazamiento no se hace efectivo hasta avanzado el siglo XVI (54).

En las carnicerías hay tablas de cerdo, vaca, y cordero, carnero y oveja. Por supuesto, no son raros los medineses que tienen cerdos (55), pero, con todo, se vende también su carne en las carnicerías, aunque parece que no sólo en ellas (56). La carne de vacuno tiene su propia tabla, donde se vende, en 1490, a 14 cornados de San Juan a San Miguel y a 5 . blancas de aquí a San Juan. Seguramente este precio se refiere a la vaca propiamente dicha, la ternera debia de ser más apreciada y su comercialización sin duda más restringida y destinada especialmente a las mesas mejor servidas (57). Como en otros lugares (58), parece que la carne preferida es la de carnero, cuyo precio en 1490, según la misma puja a la que antes me he referido, era de 4 mrs. la libra; ese mismo año la libra de cordero se pujó a 5 blancas, pudiéndose pesar las cabezas, y la de oveja a 10 cornados. El cerdo fresco se puja, como el carnero, a 4 mrs. la libra, hasta Navidad (59); la explicación de este precio tan elevado responde, sin duda, a que éste, y el carnero, son los únicos animales que se crían específicamente para carne, lo que debe hacerles especialmente apetecibles. Junto a esto quizá haya que pensar también, por una parte en el tiempo transcurrido ya desde la época de la matanza, que haría que la disponibilidad de carne de cerdo procedente de la cría casera hubiera disminuído notablemente; en que el consumo de carne fresca de cerdo no debía ser muy frecuente, y quizá por eso podía ser considerada en cierto modo un producto de «lujo»; e igualmente en la faceta ferial de Medina, que lleva a la villa a un elevado número de foráneos con recursos económicos suficientes, que buscarían carne de calidad para abastecer sus mesas.

La diferencia de precios puede dar una pista sobre las preferencias del gusto de los medineses respecto a la carne, a pesar de que en ocasiones, a la hora de precisar, no son muy finos, pues en un pleito que enfrenta al carnicero Alonso de Segovia con los fieles se habla indistintamente de cabrito, cordero y carnero para referirse al objeto del litigio: tres cuartos de alguna de estas reses, que le fueron confiscadas al carnicero, como pena por haber cobrado medio real por encima de lo establecido un cuarto que vendió a los molineros de a viento (60).

Pero el consumo de uno u otro tipo de carne no es sólo un problema de paladar, sino fundamentalmente de posibilidades económicas, que están en relación directa con la clase a que cada individuo pertenezca. Por otra parte, no se trata sólo de que la ternera y el carnero sean consumidos prefe- 
rentemente por los integrantes del más elevado escalón social, es que además éstos consumen, tratándose del mismo tipo de carne, un producto de mejor calidad. No se llega, como en Murcia, a que los carniceros, por orden del concejo, reserven la mejor carne para los pertenecientes a éste (61), pero en la práctica se tiende a ello. Así se desprende claramente de las quejas de los vecinos de los arrabales que se ven obligados a comprar en las carnicerías exentas de sisa, en las que, entre otros problemas, se les sirve por detrás de los vecinos no obligados a satisfacer la sisa, de manera que siempre les venden las sobras. Por supuesto, se quejan de ello, tratando de evitarlo, sobre todo porque parece que el ejemplo cunde, y ya no sólo es que se les postergue respecto a la clase dominante, sino al conjunto de los hombres buenos exentos, a quienes sirven, a su vez, por delante de los pecheros (62).

Por su parte, los exentos se sienten también perjudicados, en este caso porque, según la denuncia que formulan, el concejo, a través de sus fieles, hace que la mejor carne vaya a las tablas de donde comen los miembros de los linajes, de manera que ellos sólo tienen acceso a un producto de inferior calidad. Como no podía ser menos, utilizan este nuevo agravio para intentar escapar al control concejil, denunciando el hecho y pidiendo disfrutar de algo verdaderamente revolucionario: una carnicería no sometida al control de los fieles nombrados por los regidores; justifican la demanda acusando a los oficiales concejiles de utilizar la fieldad únicamente çomo instrumento de obtención de ingresos, no dudando en cometer, con ese fin, todo tipo de desmanes (63). El concejo se resiste y triunfa, pero el conflicto vuelve a poner sobre la mesa las pretensiones de los hombres buenos exentos, o, al menos, de alguno de ellos.

Las carnicerías son, pues, entre otras cosas, un instrumento de diferenciación social. Cada individuo, conforme a su condición, debe acudir a una u otra, y, además, será tratado en ella de acuerdo con su posición social. Por otro lado son, como señalaba antes, un importante medio de enriquecimiemto para unos pocos: el acceso a la carnicería se hace mediante arrendamiento, y ya hemos visto los abusos a que este mecanismo da lugar, y cómo arrendadores y algunos regidores obtienen de esta forma cuantiosos beneficios económicos. Además quienes las atienden logran también pingües ganancias.

Por lo que hace referencia a los carniceros, pueden ser considerados como parte de los protagonistas de ese intento de los más destacados exentos de sobresalir por encima del común de los vecinos, aproximándose, hasta donde fuera posible, a la clase dominante. Logran afianzar su posición mediante los recursos que les brinda la carnicería, pues el sistema imperante 
les permite enriquecerse, no sólo mediante la atención a la misma, sino también a través de los abusos a los que ya me he referido, sin olvidar el propio mecanismo del arrendamiento, que hace posible que el arrendador ceda el usufructo de la carnicería a otra persona (64).

Llegados a este punto es posible decir que parece vislumbrarse la existencia de un pequeño grupo de medineses que, sin poder llegar hasta las esferas del poder establecido, intenta hacer valer sus intereses, amparándose en la mayoría de sus convecinos, los exentos, a los que parece utilizar en su propio beneficio, aunque las reivindicaciones que plantean pueden favorecer, en mayor o menor medida, a todos ellos. Constatados estos indicios habria que intentar individualizar a los integrantes de ese grupo -entre los que parecen contarse los carniceros- con el fin de perfilar a los protagonistas de un proceso que, andando el tiempo, va a desembocar en la constitución de una nueva clase social. 

( $\left.{ }^{\star}\right)$ El presente trabajo ha sido realizado en el marco de la ayuda concedida por la D.G.I.C.Y.T. al proyecto de investigación n PB 87-0896, con el título genérico «Mundo urbano en Castilla la Vieja (fines s. XIII-comienzos s. XVI)».

(1) HILTON, R., "Las ciudades en la sociedad feudal inglesa", en Conflicto de clase y crisis del feudalismo, Barcelona, 1988, pp. 112-113.

(2) DEL VAL VALDIVIESO, M.I., «Aproximación al estudio de la estructura social de una villa mercantil castellana a fines de la Edad Media: Medina del Campo»; comunicación presentada en el coloquio internacional celebrado en Pau en septiembre de 1988 sobre Les sociétés urbaines dans la France Meridional et la Peninsule lberique au Moyen Age (en prensa).

(3) Idem

(4) A.G.S., R.G.S., 1480, octubre 14, fol. 16. No solamente se protesta por esto, también se elevan quejas cuando los miembros de la clase dominante, sin ser propiamente hidalgos, se eximen de pagar sisas, tal y como sucede en 1503 en relación con la sisa que se impuso para responder al servicio extraordinario pedido por la corona para hacer frente a los gastos derivados de la guerra con Francia (A.G.S., Cámara de Castilla, Pueblos, Leg. 12, Medina del Campo, fol. 88. En adelante se citará: Cámara, Pueblos, leg.12, fol.).

(5) HILTON, R., «iHubo una crisis general del feudalismo?», en Op.cit., p. 157.

(6) A.G.S., R.G.S., 1493, marzo 7, fol. 219. Los prados, escasos y deseados, pueden ser objeto de otros abusos; a este respecto habría que recordar el comportamiento de los propietarios de los colindantes a la dehesa y prados concejiles, quienes, aprovechándose de esa circunstancia, y de la necesidad de pastos para atender el mantenimiento de las caballerias de los mercaderes que acuden a las ferias, cobran derechos excesivos, se benefician de penas que se imponen de forma poco clara, etc.; las cosas llegan a tal extremo que la villa intenta comprar los prados de particulares lindantes con la dehesa de la Horcilla (véase DEL VAL VALDIVIESO, M.I., "Mercaderes portugueses en Medina del Campo", en Relaciones hispano portuguesas en la Edad Media, Oporto, 1987, pp. 10-15).

(7) Los procuradores de los vecinos de la villa y de la tierra sostienen que tienen derecho a estar presentes en las reuniones en las que los regidores se ocupan de temas de carácter económico, pero que no les dejan disfrutar del mismo para que no se enteren cómo y en qué se gastan los recursos concejiles (A.G.S., R.G.S., 1490, diciembre 20, fol. 94). Esta pugna les lleva a quejarse a la corona, consiguiendo que ésta ordene la realización de una pesquisa para saber si en tiempos pasados los procuradores de los vecinos (caballeros, hidalgos, exentos y pecheros) estaban presentes, o no, en las reuniones concejiles, especialmente cuando se trataba de asuntos de índole económica (A.G.S., Cámara-Pueblos, leg. 12, fol. 15). Hay que tener en cuenta que eso no es un hecho exclusivo de Medina, en la vecina Olmedo el procurador de los pecheros de la villa y su tierra se queja de lo mismo (A.G.S., R.G.S., 1494, julio 16, fol. 337).

(8) Indican que la costumbre inmemorial impone que esas causas se vean los martes, jueves y sábados, a la hora de prima en el caso de los vecinos de la villa, y a la hora de tercia 
en el de los de la tierra, siendo posible además oir otro tipo de causas diferentes a las derivadas del cobro de esa renta (A.G.S., Cámara-Pueblos, leg. 12, fol. 84 , pp. 4 y 5 ).

(9) Sobre esas irregularidades véase A.G.S., R.G.S., 1487, septiembre 19, fol. 166; y noviembre 14, fol. 17; también 1489, marzo 26, fol. 116. Este mismo año, el 7 de julio, el procurador de los exentos, Rodrigo Bayón, insiste en acusar a los regidores de apropiarse de las rentas concejiles, defraudar en el arrendamiento de las carnicerías, pescaderías y candelas (A.G.S., Cámara-Pueblos, leg. 12, fol. 17), lo que coincide exactamente con lo que los reyes mandan investigar. Este mismo procurador, al año siguiente, escribe una carta a su primo Sancho Ruiz de Cueros, secretario de los reyes, en la que solicita su intervención para evitar males mayores, ya que el corregidor Núñez de Guzmán, que ha tomado partido por los regidores, acusa a los escribanos a los que encargó la realización de la pesqui$\mathrm{sa}$, de haber actuado incorrectamente. Por su parte, los regidores se habían quejado de que habian sido llamados como testigos algunos de sus enemigos más notorios y hombres omiçidas y matadores, logrando de esta forma un careo entre Alonso Cabezudo, vecino de Pozal de Gallinas, y el pescador Juan de Zamora, del que parecía resultar que este último había hecho una falsa declaración (el de Pozal jura ser verdad lo que él dice, contrario a Zamora, en la iglesia de San Bartolomé) (ldem. fol. 19).

(10) A.G.S., R.G.S., 1489, marzo 26, fols. 423, 420, 419, 422 y 90; y marzo 28, fol. 307.

(11) A.G.S., R.G.S., 1489, marzo 28, fol. 306. En 1487 Antonio Cornejo ejecutó, en bienes de los regidores, las demasías de maravedís de que se habian apoderado a costa de los propios concejiles, según constaba en una investigación realizada al efecto devolviéndolo al concejo (Idem, 1486, marzo 26, fol. 424); Esto provoca un pleito que es sentenciado por los reyes, contra los regidores, en 1493 (véase la nota 24).

(12) A.G.S., R.G.S., 1493, marzo 12, fol. 177; julio 10, fol. 44; octubre 19, fol. 128; 1494, octubre 17, fol. 96 . Esta destitución da lugar a un pleito entre el hijo de Sancho, que acabará triunfando, y el cazador real Charles Chao. Por otra parte hay que llamar la atención sobre el regidor destituído en esta ocasión, puesto que no es la primera vez que se ve «castigado» con esta pena: en 1475 el entonces alcaide de la Mota, Francisco Girón, es nombrado regidor por los reyes, en sustitución precisamente de este Sancho Díaz, que había sido separado del cargo al ser declarado culpable de la muerte de Francisco de Villegas (A.G.S., R.G.S., 1475, febrero 7, fol. 208).

(13) A.G.S., R.G.S., 1497, mayo 4, fol. 77. En 1508 y 1509 sigue el pleito contra «el mal regimientos como puede verse, entre otros, en /dem, Cámara-Pueblos, leg. 12, fols. 131 y 142.

(14) Este Diego del Castillo había sido condenado a destierro de la villa como consecuencia de una pelea que tuvo con un carretero (A.G.S., R.G.S., 1493, noviembre 4, fol. 127).

(15) El interrogatorio se conserva en un pleito de 1503 en el A.G.S., Consejo Real, leg. 11, fol. 9-II. Este interrogatorio es de los últimos años del siglo XV, concretamente entre $1489 \mathrm{y}$ 1493, pues parece que Sancho Díaz aún es regidor, cuando es destituído de este cargo en 1493, mientras que la quinta pregunta cita como año ya pasado 1488; quizá sea de 1489, concretamente el que Rodrigo Bayón, procurador de los exentos presentó al corregidor el día 5 de enero (A.G.S., Cámara-Pueblos, leg. 12, fol. 18).

(16) Casado con Isabel de Bracamonte. Hay que señalar además que la familia de los Hebanes . ha protagonizado en los años inmediatamente anteriores un pleito contra el concejo y corregidor porque éstos pretendían arrebatarle la posesión del término de los Hevanes; quizá este reciente suceso explica la cautela que demuestran en sus respuestas este testigo y Juan Pollino (DEL VAL VALDIVIESO, M.I., «Aproximación al estudio...», Op.cit, pp. 26-27).

(17) Esta segunda pregunta dice: Yten sean preguntados sy saven, creen, vieron, oyeron dezir que los dichos regidores o la parte dellos quando se juntan en su regimiento e ayuntamiento se juntan e allegan mas para entender en las cosas que a ellos les esta vien y es su provecho que no en la dicha villa ni para el vien comun della, como quiera que en el razonamiento que hazen en el dicho ayuntamiento e leyes que ponen e azen se justifican tanto que no puede ser mejor y en la execuçion dellas nunca se an hecho ni azen cosa alguna, ante an tomado e toman de los dineros de los propios del conçejo e los an convertido en 
sus propios usos e probechos como sy suyos propios fuesen; e sean preguntados quales son estos que lo azen.

(18) En este caso puede pensarse en la existencia de una posible diferencia que entrentara a este escribano, y quizá a alguno o todos los demás, y la justicia de Medina; piénsese que este tipo de problemas no es infrecuente, y que precisamente el pleito del que procede esta información provocó uno de esos conflictos: en 1490 Sancho Rodríguez Morejón, escribano, reclama al corregidor saliente, Ramiro Núñez de Guzmán, el pago de la pesquisa que habia realizado el año anterior sobre los regidores por orden suya, cuya minuta ascendía a $5.800 \mathrm{mrs}$. La reclamación es atendida, si bien la cantidad se rebaja hasta 4.000 mrs., pero al escribano le es dificil hacer efectiva esa cantidad, y todavia en 1491 los reyes se refieren a este asunto, ordenando entonces que se satisfaga esa deuda a Morejón y a Pedro Alonso, el otro escribano que había realizado esa pesquisa (A.G.S., Cámara-Pueblos, leg. 12 , fol. 20 , y R.G.S., 1491, enero 5, fol. 185).

(19) En la sexta pregunta se plantea a los testigos sy saven etc. que ha seido y es costunbre en esta dicha villa de Medina de tienpo inmemorial acubsada e guardada que quando el dicho conçejo, justiçia, regidores an de enviar algunos mensajeros a los reyes, pasados e presentes, nuestros señores, e a otras partes que cunplan de yr que yban a los tales mensajes un honbre hijodalgo del linaje de Mercado e otro del linaje de los Pollinos desta villa, lo qual los dichos regidores han quebrantado e la an apropiado, asy por tener los salarios doblados se van ellos a las dichas mensajerías a costa e gasto de los propios del dicho conçejo.

Si en su respuesta Yañes no inculpa a nadie, aunque menciona a varios personajes, Rodrigo del Barrio hace acusaciones concretas: Dize que save que quando el dicho conçejo a de enbiar a alguna parte fuera desta dicha villa que continuamente procuran los dichos caminos el dicho Sancho Diaz, regidor, mas que otro alguno e despues del dicho Pedro de San Andrés, e questos mas continuamente van a los dichos caminos, e los pagan del dicho conçejo, e que oyo quexarse de aquesto al dicho Diego del Castillo que non avia de pagar asi quel dicho Sancho Diaz e Pedro de Sant Andres oviesen de yr de continuo los dichos caminos que por todos se avian de repartir; e questando una vez el dicho Diego del Castillo en Valladolid, procurando çiertas cosas que cunplen al dicho conçejo, algunos de los dichos regidores procuraron como ge lo quitaron e lo dieron a Rodrigo de Bobadilla que entonçes traya pleito sobre Bobadilla en Chançelleria con los fijos de Rodrigo de Bobadilla el Viejo, e que le procuraron al dicho Rodrigo de Bobadilla salario del dicho conçejo quando yba a Valladolid deziendo que yba a procurar hechos del dicho conçejo e non hera asy, que procuraba los suyos e le pagaban los dyas que alla estaba de los propios del conçejo, e como quiera que lo dezia e venia con los otros regidores de la dicha villa no le aprovechaba nada; e asy mismo enbiaron alla al dicho Pedro de Sant Andres e fueron alla, e al dicho Diego del Castillo le enbiaron a desir que se aviniese por manera quel dicho Rodrigo de Bobadilla yba a procurar su pleito e Pedro de Sant Andres a haser e procurar sus negoçios con Alonso de Quintanilla su suegro, todos a costa del dicho conçejo, e que lo vio quexarse dello al dicho Diego del Castillo diziendo que aquellos fueron alla a procurar lo quel procuraba por el dicho conçejo lo acabara el solo tan vien como ellos e so color que yncurrieran por el dicho conçejo tanvien yban a haser e procurar sus propios hechos por manera que se gastaban del dicho conçejo mucho mas de lo que se havia de gastar.

(20) A este respecto, y a título de ejemplo, puede transcribirse la respuesta de Juan de Zamora y Juan Manso a la quinta pregunta:

Juan de Camora, pescador, dize qu puede aver agora asta quatro años poco mas o menos tienpo queste testigo e Juan de Medina e Hernand Perez e Juan Manso, pescadores, veçinos desta dicha villa tovieron sacada e rematada del dicho conçejo la pescadería de la dicha villa, e non se acuerdan sy fue a seys mrs. o a seis mrs. e medio la libra e que aquel año perdieron en ella, e luego otro año segundo se ovieron consideraçcion todos ellos e se acordaron de la tornar a tomar para el otro año segundo e que uno o dos 
destos tomaron el cargo para lo fablar e consultar con el dicho Sancho Diaz, regidor, para que toviese manera como en el dicho regimiento se les rematasen la dicha pescaderia aquel año a syete mrs. la libra e que save que ge les remato a todos ellos la dicha pescaderia aquel año a razon de syete mrs. la libra, e hecho el dicho remate quedo la dicha pescaderia con ellos aquel año e por quel dicho Sancho Diaz, regidor, ge la yzo rematar en el dicho conçejo, e Hernando Alonso de los Llanos, que tenia cargo entonçes de la escribania del conçejo con el dicho Sancho Diaz, le ayudo e conçertaron entre sy de serbir al dicho Sancho Diaz con dos mill mrs. para un capus, e al dicho Fernando Alonso con veynte reales de plata, que todos ellos los repartieron entre sy e copo a este testigo de su parte para ello un castellano e medio real para dar al dicho Sancho Diaz, e çinco reales para dar al dicho Fernando Alonso, los quales este testigo dio al dicho Juan Manso para que ge los diese. $E$ esto save porque es verdad.

El XXV/ ${ }^{\circ}$ testigo, Juan Manso dixo.... e que este testigo e Hernan Perez e Hernando el Romo, pescadores, podia aver dos o tres años que hivan a regimiento a poner en preçio las serenas e en el camino toparon con Juan de Medina, carnicero, ya difunto, e les dixo que no fuesen quel benia de ponellas e no le avian querido resçebir la postura que ponia en ellas con el prometido que les demandaba, e todavya este testigo e sus conpañeros e non les dexaron entrar en regimiento; e los regidores se juntaron en la tarde en San Francisco, e este testigo e Fernando de Romo e Juan Peres, pescadores, fueron alla e entraron do los regidores estaban ya que se querian llevantar quando ellos llegaron y se llevantaron $y$ alli en el dicho monasterio el dicho Sancho Dias, regidor, que ende estava, a ellos se fue a hablar con este testigo e le dixo que fuese padrino de la boda de Alonso el Teso, su allegado, e este testigo le respondio que le dexase estar agora que no venis a eso salvo a hablar en las rentas, e le respondio como Pedro de Medina aquel dia las ponia en regimiento e non quesyeron resçebir la postura que hasyan ellos porque demandaba diez mill mrs. de prometido e este testigo dixo señor a eso benimos yo e Hernando el Romo a ponellas en preçio, e le dixo entonçes a los otros regidores sentados señores que Juan Manso e Fernando el Romo vienen a poner las serenas en preçio, que ellos se sentaron e este testigo e el dicho Fernando ante ellos les pusieron entonçes en doçientas treynta mil mrs. por aquel año con diez mill de prometido para este testigo e para Fernando el Romo e para Juan Peres e Ferran Peres e Juan de Medina; e los dichos regidores e corregidor que estavan ende resçibieron la dicha postura e les prometieron los dichos diez mill de prometido sy pujada les fuese; e despues otro dia seguiente el dicho Sancho Diaz, regidor, topo con este testigo a los canvios desta villa e le dixo que por cabsa deste testigo avian reçebido la postura de las dichas sernas y le avian prometido los dichos diez mill mrs. $y$ despues el dicho Juan de Medina, carniçero, a consentimiento de todos sus conpañeros, en regimiento fiso, sobre sy e sobre ellos, puja de veynte e mill mrs. en las dichas serenas de mas de de las doçientas e treynta e mill mrs. que este testigo les tenian puestas con çinco mill mrs. de prometido que los dichos regidores prometieron; e despues desto ge las pujaron otros que non quedaron con estos de manera que ganaron de prometido quynçe mill mrs., e en los çinco mil mrs. postrimeros del dicho prometido el dicho Juan de Medina que (borrado) escribir al dicho Sancho Diaz con çincuenta reales; e les libraron los dichos regidores al dicho Juan de Medina e a sus conpañeros los dichos quinse mill mrs., e ge los pagaron, e sirvieron al dicho Sancho Diaz çincuenta reales, los quales le dio el dicho Juan de Medina, e los dio en quenta al dicho Juan de Medina a sus conpañeros e a este testigo, e porque sopieron que hera verdad que ge los dio que los resçibieron e tomaron en quenta.

(21) Alvar Gutiérrez, según declara Rodrigo de Barrionuevo en la tercera pregunta, armó a sus hombres contra los fieles que habían confiscado ciertas mercancías a un judío amigo suyo.

(22) La pregunta en la que se hace esta denuncia, la novena, dice: sy saven, creen, vieron, oyeron desir que ha seydo y es costunbre en esta dicha villa, usada e guardada en ella de tienpo ynmemorial aca, espeçialmente en el dicho conçejo, que se guarde so grandes penas por ellos hordenadas e puestas, una dehesa de yerba que esta çerca de la dicha 
villa para mantenimiento de caballos e mulas e vestias de labrança, e que ninguno no entre en ella con ganado ovejuno ni vacuno so pena que los diezmen los dichos ganados, e los dichos regidores e los que dellos los tienen asolutamente echan o hasen hechar sus ganados ovejunos e vacunos en la dicha dehesa de dya e de noche en verano e en ynbierno como sy suya propia fuese, e que si las guardas les montan e prenden los dichos sus ganados an ydo e van a sus casas de las dichas guardas o envian a las amenazar o matar e tomanles las dichas montas que les hasen por fuerça; e sean preguntados los regidores an hecho esto o mandan lo haser.

A esta pregunta Alonso Nieto responde que puede aver agora tres años poco mas o menos que traiendo su pastor de este testigo cierto ganado bacuno suyo en los prados de la Orzilla que tres cabezas dellas se fueron a la dicha desa e que una guarda que se llama Pedro Obispo que vive al varrio de Santo Esteban las prendo e llevo a su casa e las tobo vien tres dyas en su corral syn comer ni vever, e que las andaban a buscar los de su casa e no sabian donde estaban asta tanto que este testigo ovo de saver que estaban alli e fue alla e abrio el dicho corral e las hecho fuera e denosto a la dicha guarda que las tenia alli tantos dias sin comer e vever q quel le respondio mal e le dixo este testigo que le quebrantaria la cabeça porque tan mal lo avia hecho e que sy algunos ganados ovejunos entran de noche e de dya en la dicha desa sera por culpa de los pastores que los guardan, mas no porque los señores de los ganados ge lo manden, queste testigo sepa.

(23) La séptima pregunta les interroga sobre sy saven, oyeron que los dichos regidores o alguno o algunos dellos han amenazado e amenazan en los tienpos pasados y aun agora al procurador de los buenos honbres exentos desta dicha villa e a los otros procuradores e quadrilleros de las quadrillas de la dicha villa por que non consyenten ni han consentido en el dicho su ayuntamiento e conçejo que hazen en algunas cosas que son deserviçio de Dios e de sus altezas e del vien comun de la dicha villa e veçinos della, que los mataran a palos en sus casas e a otros de las dichas quadrillas que son sus allegados e apaniaguados los ruegan e trahen que sean e favorescan lo quellos quieren que se aga y asy se a hecho e azen; e digan e declaren los dichos testigos quien e quales de los dichos regidores lo an hecho e procurado e azen e procuran e que formas e maneras a tenido e tiene para ello.

En su respuesta, Juan de Cuenca, tundidor, dize que save ques verdad lo contenido en la dicha pregunta, porquel dicho Albar Gutierres, regidor, avellaco e amenaso mucho a Juan Peres, procurador de los honbres buenos esentos desta dicha villa por que no queria consentir en algunas cosas de las quel conçejo e el dicho Albar Gutierres hizieran o querian haser, espeçialmente sobre quel dicho Albar Gutierres procuro mucho con algunos de los ofiçiales de los dichos honbres esentos para que rebocasen de procurador al dicho Juan Peres e aun a este testigo le rogo Alonso Nieto, regidor, que estoviesen con algunos de los dichos ofiçiales e buenos honbres de la dicha comunidad e les consejase que non tomasen quistion ni porfia con los dichos regidores e que este testigo travajo e yzo lo que pudo por los conçertar a los unos e a los otros.

(24) Recuérdese que, como se dice expresamente en la sexta pregunta, las mensajerías o 'caminos' correspondian, por derecho propio, a un hidalgo de los Pollino y otro de los Mercado, pero en la fecha del conflicto esa costumbre no se guardaba y ese tipo de representación era asumido por cualquier miembro del concejo, a juzgar por lo que dice Rodrigo de Barrionuevo, especialmente Sancho Diez y Pedro de San Andrés. Sobre este particular pueden verse también las preguntas cuarta, décimosegunda y décimocuarta.

Por otra parte, junto a todas las acusaciones concretas que se hacen en el pleito, los exentos formulan también otras, en parte complementarias; entre ellas la más importante se refiere a que los regidores en vez de nombrar personas hábiles para el desempeño de los diversos oficios concejiles, ponen en esos puestos a sus amigos, criados y paniaguados, con lo que el gobierno de la villa se resiente notablemente (A.G.S., R.G.S., 1498, octubre 30, fol. 200). Además, en 1493 Pedro de Mercado, Gutierre Rodríguez de Monsalvo, Diego del Castillo y las viudas de Diego Barrientos y Alvaro de Lugo son condenados a 
restituír al concejo aquello que, según se ha demostrado en la toma de cuentas realizada (véase nota 11) - a raíz de una denuncia al respecto- por Sancho de Castilla, han cobrado en demasia (Idem, 1493, octubre 11, fol. 142). Varios años después, en 1498, el corregidor y los regidores son acusados de favorecer a los suyos dándoles, a costa del concejo, telas para guardar el luto oficial por la muerte de la hija de los reyes (Idem, 1498, septiembre 5 , fol. 268).

(25) A.G.S., Cámara-Pueblos, leg. 12, fol. 84 , pp. 4 y 5 .

(26) No hay que perder de vista que además tienen que luchar con la corriente contraria, es decir, los intentos individuales de pequeños colectivos de evitar su contribución, hecho frente al cual buscan defenderse mediante la intervención real (A.G.S., Cámara-Pueblos, leg. 12, fol. 88 , donde se menciona a regidores, letrados, escuderos, físicos, cirujanos y monederos que sin ser hidalgos rehúsan pagar la sisa impuesta para satisfacer el servicio destinado a sufragar los gastos de la guerra con Francia).

(27) A.G.S., Mercedes y Privilegios, leg. 1, fol. 844 (franqueza concedida en 1419); R.G.S., 1475, marzo 15, fol. 224 (confirmación general); Mercedes y privilegios, leg. 23, fol. 66 (confirmación de agosto de 1477; otra similar se conserva en el Archivo Municipal de Medina del Campo (en adelante A.M.M.C.), leg. 1); Patronato Real, $n^{\circ} 5089$ (traslado del documento de 1477 fechado en 1482 ).

(28) En 1493 y 1494 se recuerda a Medina del Campo esa limitación (A.G.S., R.G.S., 1493, agosto, fol 41; 1494, marzo 17, fol. 79; y Cámara-Pueblos, leg. 12, fol. 25).

(29) Tras la expulsión de los judios, los exentos medineses se dirigen a la corona protestando por el perjuicio que se les hace al repartirse entre ellos lo que hasta entonces satisfacian los judíos para contribuír a la Hermandad (A.G.S., R.G.S., 1493, marzo 26, fol. 129), y en 1496 una carta real, autorizando la imposición de una sisa, se refiere a la encarnizada resistencia que los medineses han protagonizado para evitar que lo que les correspondía pagar para el mantenimiento de los peones de la Hermandad se recaudara mediante repartimiento (Idem, 1496, enero 26 , fol. 82 ); sobre el sentido que pueda dársele a esta resistencia véase el apartado 3 de este trabajo.

(30) A.M.M.C., leg. 408, caja 567.

(31) A.G.S., R.G.S., 1494, julio 19, fol. 126.

(32) A.G.S., R.G.S., 1494, mayo 1, fol. 14 (pago por tercios); Cámara-Pueblos, leg. 12, fol. 3 (condiciones del arrendamiento de la sisa en que se habla, entre otras cosas, de un fiel encargado de la misma), y fol. 27 (queja contra la sisa); R.G.S., 1494, octubre 31, fol. 16 (tapias cortafuegos).

(33) A.G.S., R.G.S., 1498, abril 7, fol. 109.

(34) Así lo hacen cuando pretenden que la compra del prado de la Horcilla se sufrague con los recursos provenientes de los propios y no por sisa, ya que ésta supondría que serían ellos, los exentos, quienes cargarían con esa responsabilidad económica, quedando al margen de la misma la clase dominante (A.G.S., Consejo Real, leg. 635, fol. 6).

(35) A.G.S., R.G.S., 1489, diciembre 2, fol. 106; 1494, mayo 6, fol. 434; Cámara-Pueblos, leg. 12, fol. 30. En 1495 esa contribución a la Hermandad provoca una auténtica conmoción en Medina, porque los exentos, alegando «las fatigas" sufridas en defensa de los reyes, dicen estar eximidos del pago de los $62.000 \mathrm{mrs}$. que corresponden a la villa, pretendiendo así que se satisfagan con los propios. El corregidor no ve las cosas de la misma manera, por lo que encarceló a más de cuarenta vecinos y los tuvo presos hasta obtener de ellos prendas -dicen los afectados - por un valor superior a $200.000 \mathrm{mrs}$., las cuales fueron vendidas fuera de la villa, causándoles con ello -insisten- gravísimos perjuicios (A.G.S., Cámara-Pueblos, leg. 12, fol. 38). El 26 de enero de 1496 una carta real vuelve a referirse al mismo conflicto, autorizando que esa contribución se recaude mediante sisa (A.G.S., R.G.S., fol. 82).

(36) A.G.S., Consejo Real, leg. 1, fol. 8-I (año de 1503).

(37) En 1495, para satisfacer la deuda que tienen contraída con su procurador, Juan Pérez, al que, por falta de recursos, no le han pagado ni el salario ni los gastos que ha tenido 
que realizar en el cumplimiento de su función, se pretende que el concejo ayude a los exentos. Estos pretenden que los $29.496 \mathrm{mrs}$. que adeudan sean pagados de las rentas concejiles, pero el corregidor y regidores declaran que eso representaría un importante agravio contra los caballeros y los hidalgos, señalando, además, que no tienen recursos suficientes para ello, causas por las que los exentos deben pagarlo "de sus bolsas». El 31 de enero de 1496 los reyes ordenan que, de momento, el concejo preste a la comunidad de hombres buenos exentos esa cantidad (A.G.S., R.G.S., 1495, abril 9, fol. 274; 1496, enero 31, fol. 129).

(38) En 1490 el concejo libra a su procurador, Juan Pérez, $10.000 \mathrm{mrs}$. para que puedan atender a sus necesidades (A.M.M.C., leg. 30, libro de acuerdos de 1490, 29 de enero). En 1498 logran convencer a los reyes de los perjuicios que sufrirían si no pudieran defender sus intereses en la corte por no poder acudir a ella a causa de su falta de recursos; en respuesta a estos argumentos, los reyes ordenan al corregidor de Medina del Campo que cada año se les pague, de los propios, $3.000 \mathrm{mrs}$. para que puedan cubrir esos gastos (A.G.S., R.G.S., abril 7, fol. 20; agosto 16, fol. 202).

(39) Téngase en cuenta que éstas, en muchas ocasiones, benefician directa y fundamentalmente a los integrantes de la clase dominante; a este respecto puede verse DEL VAL VALDIVIESO, M.I., "La vulnerabilidad de los núcleos urbanos bajomedievales: Los incendios de Medina del Campo y sus consecuencias», en Homenaje al profesor Torres Fontes, T.II, Murcia, 1987.

(40) A.G.S., Cámara-Pueblos, leg. 12, fol. 39.

(41) A.G.S., R.G.S., 1498, agosto 18, fol. 189.

(42) A la primera pregunta de la citada probanza, el testigo Diego de Medina, bachiller, dixo que lo sabe porque este testigo vio las carneçerias de sysa e syn sisa e vio como Alonso Cavallero, vecino de la dicha villa de Medina, tovo arrendada la sysa que se hecho para el serviçio de vuestra alteza e vio como el dicho Alonso Cavallero como tal arrendador tenia puesto un honbre en las dichas carneçerias donde no avia sysa para viese a los que yban a tomar carne de la dicha carneçeria y los mandavan prender algunos vecinos de los dichos arrabales, los nombres de los quales este testigo no se acuerda, e questo que dicho a puede aver en tienpo en la dicha pregunta contenido (aproximadamente 11 años) porque aun este testigo le fue dicho de los que tenian el cargo que no comiese de la carneçeria de los hidalgos syno que podria ser prendado, salvo sy no fuese porque hera este testigo bachiller e presona honrada e por su ofiçio e por esto no la prenderia, e questo sabe desta pregunta e por esto lo sabe, la qual dicha sysa fue para pagar çierto serviçio que vuestra altesa quiso servir desta dicha villa e sus arrabales.

Francisco López, al responder a la cuarta pregunta dixo que lo sabe porque en el dicho tienpo este testigo vio como Alonso Cavallero, veçino desta villa, como arrendador que a la sazon hera de la dicha sysa, tenia puesto un honbre en la carneçeria de los hidalgos $q$ que auando alguno de los buenos honbres pecheros yba alli por carne veia este testigo que los prendavan porque fuesen por carne a la carneçeria de la dicha sysa e que este testigo con aquel themor que no le prendasen como veçino de los arrabales se yba por carnal a la carneçeria de la sysa e por esto lo sabe.

Por su parte, Cristóbal de Becerril contestó así a la sexta pregunta: que lo sabe porque este testigo ha visto que en la dicha villa de Medina ay dos carneçerias señaladamente para los hidalgos e que la una questa mas çerca de los dichos arrabales, ha visto e vee este testigo que della comen los hidalgos e muchos de los buenos onbres esentos e que eso mismo ha visto este testigo que todos los buenos onbres pecheros de los dichos arrabales comen de las carneçerias de la dicha sysa, e queste testigo ha visto e vee que sy por aventura alguna bez va alguno de los buenos honbres pecheros de los dichos arrevales por carne a la dicha carneçeria de los hidalgos de la peor carne que tienen a cabsa de conplir primero con los dichos hidalgos e omes hesentos, e le detienen alli e se va ayn ello e asy comen de la dicha carneçeria de la sysa e pagan otra bez el dicho serviçio por repartimiento. segund que la dicha pregunta lo dize e por esto lo sabe. 
(43) A.G.S., Consejo Real, Leg. 1, fol. 8,II.

(44) ldem.

(45) $E \mid$ «lapsus» del escribano se produce en un documento referido al enfrentamiento de éstos con los regidores (A.G.S., R.G.S., 1487, septiembre 19, fol. 166). Como ejemplo de actua. ción conjunta de hidalgos y exentos se puede traer a colación el ruego dirigido a la reina en 1507 para que no se saque pan hacia Portugal u otro lugar de fuera del reino (A.G.S., Cámara-Pueblos, leg. 12, fol. 126).

(46) Un indicio de ésta puede quizá rastrearse en la denuncia que formulan contra los regidores, no de forma coyuntural y pasajera, sino como fruto de una actitud consciente. Esta denuncia se hace con intención firme de poner coto a la actuación del regimiento, sin que los denunciantes se retraigan por lo prolongado del pleito; como hemos visto mantienen su postura prácticamente inalterable durante varios años, lo que indica que responde a una estrategia concreta cuyo objetivo parece ser alcanzar la posición de los denunciados, no por las vías tradicionales del parentesco (de sangre o feudal), sino como premio a su fortuna y sus méritos personales.

(47) FALCON, «La alimentación en Aragón en la segunda mitad del siglo XV: el caso de Zaragoza", en Manger et boir au Moyen Age, T. 2, p. 211. Frente a esta postura Rucquoi concluye que en el Valladolid del siglo XV la carne no puede ser considerada, en absoluto, un producto de lujo, que únicamente las aves, reservadas para los que llama «los ricos» pueden merecer ese tratamiento ( $₫$ Alimentation des riches, alimentation des pauvres dans une ville castillane en XVème siècle», en Idem, p. 300).

(48) En Medina del Campo esta última posibilidad está enormemente restringida, debido a la prohibición real que afecta a su término (DEL VAL VALDIVIESO, M.I., «Medina del Campo en la época de los Reyes Católicos", en Historia de Medina del Campo y su Tierra, T. 1, Valladolid, 1987, p. 239).

(49) MARTINEZ GARCIA, «La asistencia material en los hospitales de Burgos a fines de la Edad Media», en Manger et boir, 1, pp. 354-356. MOLENAT, "Menus des pauvres, menus des confrères à Tolede dans la deuxièmme moitié du XVème siècle», en ldem, pp. 314-317.

(50) En Medina del Campo, en el repetidamente citado pleito de los exentos contra los regidores, uno de los testigos dice haber ido a la carnicería a comprar sebo para su carreta; mientras que en un conflicto que estalla entre el carnicero Alonso de Segovia y los fieles, éstos prenden a aquel tres cuartos de cordero «con su pelleja» (A.G.S., Cámara-Pueblos, leg. 12, fol. 21). Sobre sebo y pieles de los animales puede verse también el caso del carnicero Garcia Sánchez (A.G.S., R.G.S., 1478, febrero 18, fol. 125). Para otros casos puede verse FALCON, Op. cit, pp. 211-212 (Zaragoza) y RODRIGUEZ LLOPIS, Señoríos y feudalismo en el reino de Murcia, p. 267.

(51) Esto se aprecia tanto en Medina del Campo como en otros lugares, entre ellos Murcia Véase MARIN GARCIA, «Las carnicerías y el abastecimiento de carne en Murcia (1450-1500)», en Miscelánea Medieval Murciana, XIV, 1987-1988, p. 51).

(52) A este respecto véase las condiciones de las posturas de las tablas de cordero que hicieron los hermanos Manso el 16 de marzo de 1490 (A.M.M.C., Libro de acuerdos de 1490 , fol. 16V).

(53) A.G.S., R.G.S., 1496, diciembre 15, fol. 286 (los reyes dicen que si esas nuevas tablas son perjudiciales para la sisa y para la comunidad de exentos deben ser cerradas); Consejo Real, leg. 1, fol. 8-II.

(54) A.G.S., R.G.S., 1480, octubre 30, fol. 108; Cámara-Pueblos, leg. 12, fols. 93 y 94 . El traslado, como se dice en la solicitud de autorización de enero de 1499, no perjudica a los «dueños de los sitios» de las carnicerías, ya que proyectan compensarles con la entrega de «sitios» similares allí donde se ubiquen las nuevas. Parece, por lo que señala el mismo documento, que esos «sitios» son de algunas iglesias y de algunos vecinos particulares, pero no sabemos exactamente de quienes.

(55) Entre los acuerdos del concejo tomados en 1490 hay varios referentes a los cerdos propiedad de los vecinos, entre ellos los acuerdos de 8 y de 26 de enero. Por otra parte, cuando 
se cayó un lienzo de la cerca, destruyendo la casa de Diego de Cerecedo, el concejo culpa al vecino de haberla socavado para construír un establo para bestias y una pocilga para cerdos (A.G.S., Cámara, Memoriales, leg. 171, fols. 1 y 72).

(56) En junio de 1490 Rodrigo Manso «puso» el tocino añejo a $7 \mathrm{mrs}$. la libra, el salado nuevo, de treinta dias en adelante, a 5'5 mrs. y el cerdo fresco a $4 \mathrm{mrs}$. hasta Navidad (A.M.M.C., Libro de acuerdos de 1490 , fol. 38r). Como puede observarse el proceso de conservación del tocino hace subir notoriamente su precio, mientras que la carne de cerdo fresco tiene exactamente el mismo precio que el tocino salado no añejo. Por supuesto, la existencia de esta tabla no es excepcional (véase a título de ejemplo ARIZAGA, «La alimentación en el País Vasco en la Baja Edad Media: el caso de Guipúzcoas, en Manger et boire au Moyen Age, T. 2, p. 202), pero parece que el tocino y cerdo fresco se vendían también fuera de las carnicerías, ya que en el cuaderno de arrendamiento de la sisa de 1494 se le impone, como al resto de la carne, un cornado por libra, pero aclarando que debe de pesarse en el peso que señale el arrendador, fiel o cogedor bajo pena de $500 \mathrm{mrs}$. y la pérdida de la mercancía, cosa que no se señala en el caso de las otras carnes (A.G.S., Cámara-Puebios, leg. 12, fol. 3).

(57) A.M.M.C., Libro de acuerdos de 1490, fol. 38r-v. Las únicas noticias que tenemos respecto a la ternera se refieren a los abusos de los regidores, quienes, según sus acusadores en el pleito repetidamente citado, exigían, para rematar las carnicerías, unos toros, que luego se corrían en las fiestas de la villa, y ciertas terneras que se repartían entre sí y con el corregidor. Otros testigos dicen que en algunos casos los carniceros les regalaban alguna pieza de ternera o de carnero para atraer su voluntad o mantenerles a su favor (A.G.S., Consejo Real, leg. 11, fol. 9-11, pregunta 10 ; Cámara-Pueblos, leg. 12, fol. 114.

(58) Tal es el caso de Murcia (Véase MENJOT, «Notes sur le marché de l'alimentation et la consommation alimentaire à Murcie à la fin du Moyen Age», en Manger et boir au Moyen Age, 2, p. 201) y de la Toscana italiana (Véase REDON, «Les usages de la viande en Toscane au XIVème. siècle», en Idem, p. 123).

(59) No en todos los lugares ocurre lo mismo; por ejemplo, en Baeza, las ordenanzas establecen que el puerco se venda al preçio de la vaca (ARGENTE DEL CASTILLO y RODRIGUEZ MOLINA, «Reglamentación de la vida de una ciudad en la Edad Media. Las ordenanzas de Baeza», en Cuadernos de Estudios Medievales, VIII-IX, Granada, 1983, p. 61).

(60) A.G.S., Cámara-Pueblos, leg. 12, fol. 21.

(61) MARIN GARCIA, Op. cit., p. 93.

(62) A.G.S., Consejo Real, leg. 1, fol. 8-ll. Algunos como el pintor Francisco de Madrigal, dicen, dramatizando la situación, que sólo les venden pescuezos e huesos, mientras otro testigo apostilla declarando que lós carniceros les dicen aguardad, daremos al corregidor e regidores e palacios e despues, si algo queda, darosemos a vosotros. Parece que algo parecido les sucede en la carniceria de la sisa.

(63) Los documentos que se conservan de este nuevo pleito están fechados en 1503 (A.G.S., Consejo Real, leg. 11, fol. 9-1).

(64) García Manso traspasó, el 29 de junio de 1490, la tabla de vaca y carnero de San Antolín a Pedro Bermejo y Juancho de Oñate, y una de las cuatro tablas, también de vaca y carnero, de San Francisco a Fernando de los Moros, otra a Alvar Bermejo y Lope de Vergara, y otra más a Diego de Escalante, todos vecinos de Medina del Campo (A.M.M.C., Libro de acuerdos de 1490 , fols. $38 \mathrm{r}-39 \mathrm{v}$ ). 